\title{
ВЛИЯНИЕ ПРОЦЕССОВ РАДИАЦИОННОГО НАГРЕВА И ИСПАРЕНИЯ КАПЕЛЬ НА ЭКРАНИРУЮЩИЕ СВОЙСТВА ПРОТИВОПОЖАРНЫХ ВОДЯНЫХ ЗАВЕС
}

Виноградов А.Г. ${ }^{1}$, канд. физ.-мат. наук, Яхно О.М. ${ }^{2}$, доктор техн. наук

1 Черкасский институт пожарной безопасности им. Героев Чернобыля, ул. Оноприенко, 8, Черкассы, 18034, Украина

${ }^{2}$ Национальный технический университет Украины "Киевский политехнический институт", проспект Победы, 37, Киев, 03056, Украина

Виконано аналіз нагрівання й випаровування крапель розпиленої води випромінюванням осередку пожежі. Досліджено вплив цих процесів на екрануючі властивості водяних завіс. Для типових режимів теплового екранування виконано розрахунки й отримано графічні залежності параметрів, що характеризують випаровування крапель.
Выполнен анализ нагрева и испарения капель распыленной воды излучением очага пожара. Исследовано влияние этих процессов на экранирующие свойства водяных завес. Для типичных режимов теплового экранирования выполнены расчеты и получены графические зависимости параметров, характеризующих испарение капель.
The analysis of heating and evaporation of droplets of the sprayed water by the radiation of the seat of fire is made. Influence of these processes on the shielding properties of water curtains is investigated. The calculations for the typical modes of thermal shielding are executed and graphic dependences of the parameters characterizing evaporation of droplets are received.

Библ. 9, рис. 5.

Ключевые слова: противопожарная водяная завеса; экранирование теплового излучения; испарение капель.

$b_{0}$ - радиус выходного отверстия оросителя;

$c_{w}$ - удельная теплоемкость воды;

$D$ - диаметр капли;

$D_{\text {eq }}$ - эквивалентный диаметр капель завесы;

$h$ - высота водяной завесы;

$H$ - коэффициент пропускания водяной завесы;

$I_{1}$ - интенсивность падающего излучения;

$I_{2}$ - интенсивность проходящего излучения;

$L$ - удельная теплота парообразования воды;

$l_{e q}$ - толщина эквивалентного слоя воды;

$Q_{\text {nоz }}$ - расход воды оросителя;

$R$ - радиус капли;

$T_{f}$ - эффективная температура очага пожара;

$t_{f l}$ - время пролета капель вдоль завесы;

$u_{0}$ - начальная скорость капель;

\section{Введение}

Одним из средств защиты от мощного теплового излучения в зоне пожара являются водяные завесы, т.е. определенным образом расположенные в пространстве струи распыленной воды (СРВ)
$W_{1}$ - падающий на завесу тепловой поток;

$W_{2}$ - проходящий через завесу тепловой поток;

$W_{a b s}$ - тепловой поток, поглощенный завесой;

$W_{d, a b s}-$ тепловой поток, поглощенный каплей;

$x$ - вертикальная координата;

$\Delta T d$ - приращение температуры капли;

$\Delta z$ - расстояние между оросителями;

$\eta$ - коэффициент пропускания капли;

$\lambda$ - длина волны излучения;

$\rho_{a}-$ плотность воздуха;

$\rho_{w}$ - плотность воды;

$\tau_{b}$ - время нагрева капли до точки кипения;

$\tau_{e v}$ - время испарения капли;

$\varphi_{\theta}$ - угол раствора распыленной струи;

СРВ - струя распыленной воды.

[1-4]. Для создания водяных завес используются дренчерные оросители, позволяющие создать плоские веерные СРВ, форма которых наиболее соответствует задаче теплового экранирования.

Расчет экранирующих свойств водяной завесы 
может быть выполнен с помощью математической модели, позволяющей на основе технических параметров дренчерной системы и параметров очага пожара определить коэффициент пропускания теплового излучения пожара [5 - 8]. В модели учтены основные физические процессы, влияющие на параметры теплового экранирования (гидроаэродинамика распыленной струи, взаимодействие теплового излучения с каплями СРВ), однако некоторые важные аспекты данной модели требуют дополнительного исследования. В частности, необходимо исследовать вопрос о нагреве капель СРВ тепловым излучением пожара и их испарении.

Испарение капель сопровождается уменьшением их диаметра и влияет на экранирующие свойства водяной завесы. Необходимо установить, какие параметры влияют на скорость радиационного нагрева и испарения капель, найти соответствующие функциональные зависимости и выполнить численные расчеты для типичных режимов экранирования теплового излучения пожаров. На данном этапе речь идет лишь об оценочных расчетах, на основании которых можно будет сделать вывод о том, насколько существенными являются указанные процессы и нужно ли их учитывать при построении математической модели экранирования теплового излучения пожаров с помощью водяных завес.

\section{Схема процесса теплового экранирования}

На рис. 1 представлена схема процесса экранирования теплового излучения. Первичное излучение интенсивностью $I_{1}$ от очага пожара падает на дренчерную завесу высотой $h$ и толщиной $l$. Часть лучистого теплового потока $W_{a b s}$ поглощается каплями (вследствие чего их температура повышается) и дальше проходит ослабленное излучение интенсивностью $I_{2}$.

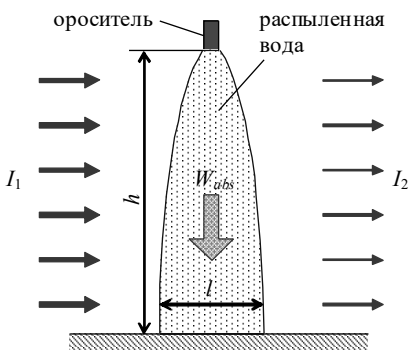

Рис. 1. Схема процесса теплового экранирования дренчерной завесой.

\section{Математическая модель}

Коэффициентом пропускания водяной завесы называется величина:

$H=\frac{I_{2}}{I_{1}}$.

Согласно математической модели, представленной в работах $[7,8]$, расчет коэффициента пропускания может быть выполнен с помощью соотношения:

$$
H=\exp \left[-1,4 \cdot(1-\eta) \cdot \frac{l_{e q}}{D_{e q}}\right],
$$

где все три величины в правой части формулы $\left(\eta, l_{e q}, D_{e q}\right)$ зависят от размера капель. Таким образом, уменьшение размера капель в процессе их испарения должно повлиять на величину $H$.

Вначале рассмотрим процесс радиационного нагрева и испарения капель, исходя из интегральных характеристик: общей мощности падающего на завесу и проходящего излучения пожара; общего расхода воды; общего количества теплоты, необходимого для нагрева и испарения этой воды.

Поскольку расчет носит оценочный характер, будем считать, что водяная завеса, созданная $N$ оросителями, имеет форму прямоугольника высотой $h$, шириной $Z_{c}=N \cdot \Delta z$ и площадью

$\mathrm{S}=Z \cdot h=N \cdot \Delta z \cdot h^{c}$.

Падающий на водяную завесу и проходящий через нее тепловые потоки:

$W_{1}=I_{1} \cdot S$,

$W_{2}^{1}=I_{2} \cdot S=H \cdot I_{1} \cdot S$.

Тепловая мощность, поглощаемая водяной завесой и расходуемая на нагрев и испарение капель:

$W_{a b s}=W_{1}-W_{2}=I_{1} \cdot S \cdot(1-H)$.

Общий расход воды всех оросителей (объем в единицу времени):

$Q_{s}=N \cdot Q_{n o z}=N \cdot \pi \cdot b_{0}^{2} \cdot u_{0}$.

Если температура всей воды за время пролета капель повышается в среднем на $\Delta T$ и испаряется часть этой воды $\Delta Q_{s}=k \cdot Q_{s}$, где $k$ - объемная доля испарившейся воды, то можно написать уравнение теплового баланса (пренебрегая тепловым излучением капель):

$W_{a b s}=c_{w} \cdot \rho_{w} \cdot Q_{s} \cdot \Delta T+L \cdot \rho_{w} \cdot \Delta Q_{s}$,

или 
$I_{1} \cdot \Delta z \cdot h \cdot(1-H)=\rho_{w} \cdot \pi \cdot b_{0}^{2} \cdot u_{0} \cdot\left(c_{w} \cdot \Delta T+k \cdot L\right)$.

Отсюда можно определить плотность мощности падающего теплового излучения, которой достаточно для испарения объемной доли $k$ всей воды, содержащейся в каплях водяной завесы, за время их пролета:

$I_{1}(k)=\frac{\rho_{w} \cdot \pi \cdot b_{0}^{2} \cdot u_{0} \cdot\left(c_{w} \cdot \Delta T+k \cdot L\right)}{\Delta z \cdot h \cdot(1-H)}$.

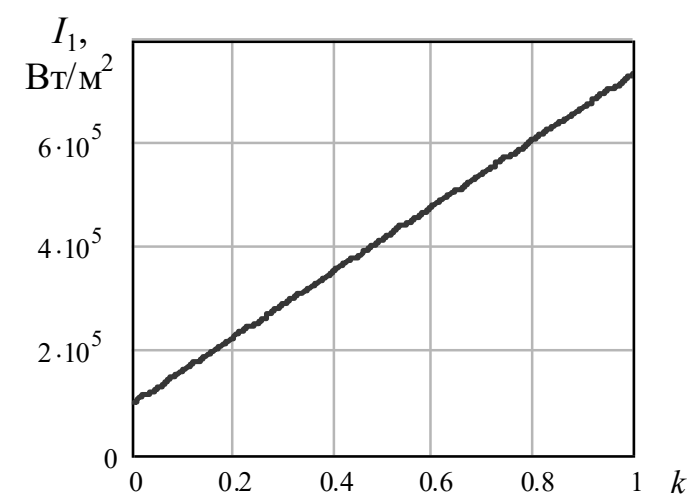

Pис. 2. Зависимость $I_{1}(k)$.

На рис. 2 представлен расчетный график зависимости $I_{1}(k)$ для типичных параметров $b_{0}=3 \mathrm{MM}, u_{0}=20 \mathrm{M} / \mathrm{c}, \Delta T=80 \mathrm{~K}, \Delta z=0,5 \mathrm{M}, h=5 \mathrm{M}$, $H=0,2$.

Данный расчет свидетельствует о том, что при заданных параметрах процесса даже катастрофический пожар с интенсивностью теплового излучения около 200 кВт/м² способен испарить воду из капель водяной завесы лишь на $17 \%$. Для типичных же значений интенсивности излучения пожаров $20 \ldots 40 \mathrm{kBT} / \mathrm{M}^{2}$ существенного испарения общего количества воды не произойдет.

Однако этот результат получен для интегральных характеристик водяной завесы и не учитывает ряд особенностей, которые влияют на процесс испарения отдельных капель. Распыленная струя состоит из капель разных размеров, в соответствии с некоторой функцией распределения. Пребывая в равных условиях, за одно и то же время мелкие капли нагреваются до точки кипения и частично или полностью испаряются, а крупные капли не успевают нагреться до кипения и почти не испаряются.

Выполним оценочный расчет минимального времени нагрева капли диаметром $D$ до темпе- ратуры кипения. Поглощенная каплей энергия теплового излучения расходуется на ее нагрев, испарение и испускание теплового излучения. Как показывают оценки, последним фактором при температурах капли менее $100{ }^{\circ} \mathrm{C}$ можно пренебречь. Время нагрева капли $t$ будет минимальным при отсутствии ее испарения. При этих условиях вся поглощенная каплей энергия будет израсходована на ее нагрев с изменением ее температуры на $\Delta T_{d}$ :

$W_{d, a b s} \cdot t=c_{w} \cdot \rho_{w} \cdot \frac{\pi D^{3}}{6} \cdot \Delta T_{d}$,

где поглощенный каплей тепловой поток [5]:

$W_{d, a b s}=0,934 \cdot \frac{\pi D^{2}}{4} \cdot(1-\eta) \cdot I_{1}$.

Коэффициент пропускания капли $\eta$ зависит от диаметра капли $D$ и от эффективной температуры очага пожара $T_{f}$ В приближении излучения абсолютно черного тела $[7,8]$ :

$\eta=A \cdot D^{B}+C$,

$A=1,25 \cdot 10^{-35} \cdot\left(T_{f}-207,6\right)^{11,02}$,

$B=-2,329+1,6362 \cdot 10^{-3} \cdot T_{f}+1,0519 \cdot 10^{-6} \cdot T_{f}{ }^{2}-$

$-1,386 \cdot 10^{-9} \cdot T_{f}^{3}+5 \cdot 10^{-13} \cdot T_{f}^{4}-0,651 \cdot 10^{-16} \cdot T_{f}{ }^{5}$,

$C=-9,59 \cdot 10^{-5} \cdot 10^{0,002495 T_{f}}$.

Минимальное время нагрева капли до точки кипения $\tau_{b}$ найдем из (3) и (4), полагая начальную температуру воды около $20^{\circ} \mathrm{C}$ и $\Delta T_{d}=\Delta T_{b} \approx 80 \mathrm{~K}$ : $\tau_{b}=\frac{c_{w} \cdot \rho_{w} \cdot D \cdot \Delta T_{b}}{1,4 \cdot(1-\eta) \cdot I_{1}}$.

Из работы [7] найдем минимальное время пролета капель на расстояние $h$ :

$t_{f l}=\int_{0}^{h} \frac{d x}{u_{m}(x)}=$

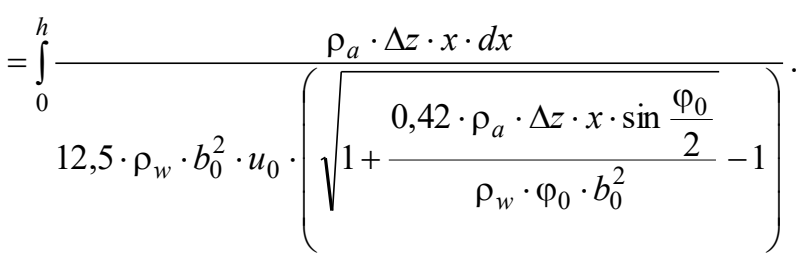

На рис. 3 представлен расчет зависимостей $\tau_{b}(D)$ и $t_{f t}(h)$ для типичных параметров $b_{0}=3 \mathrm{мм}$, $\varphi_{0}=2,5$ рад, $\Delta z=0,5 \mathrm{M}, T_{f}=1200$ К и для указанных на рисунках значений $I_{1}$ и $u_{0}$. 

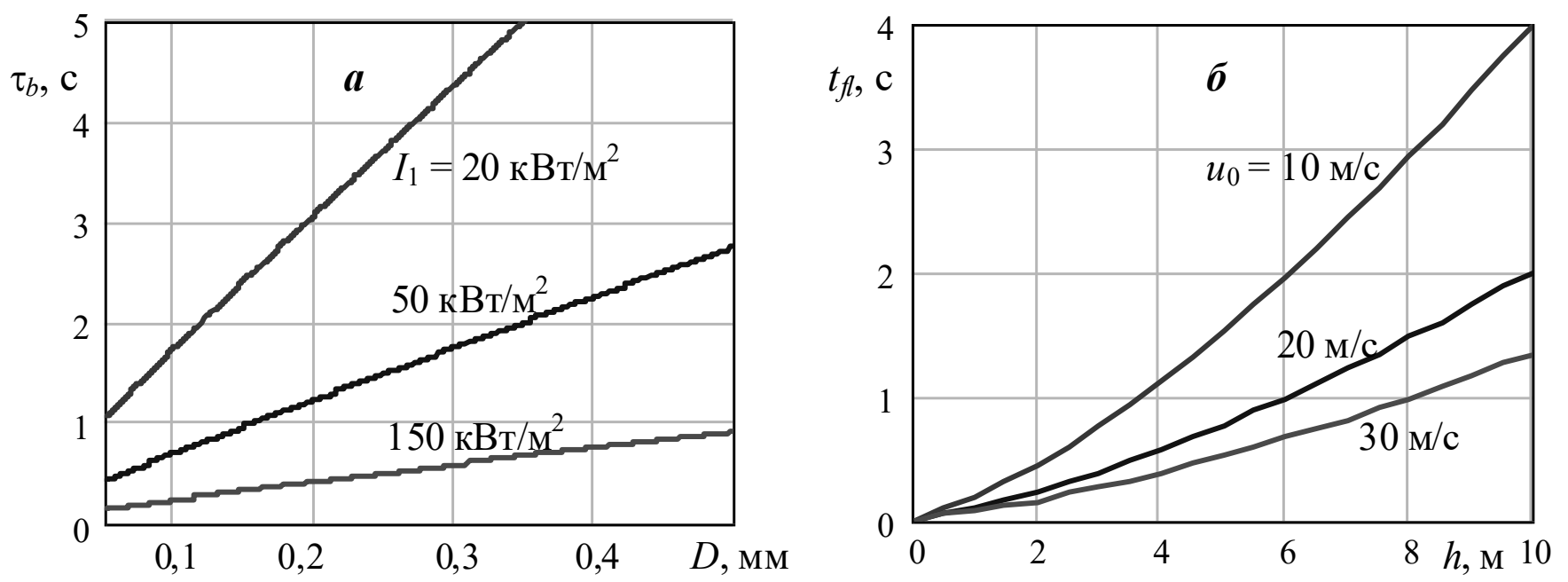

Рис. 3. Результаты расчета: а) времени нагрева капли до точки кипения; б) времени пролета капли вдоль высоты водяной завесы.

Сравнивая расчетные значения $\tau_{b}$ и $t_{f f}$, можно увидеть, что это величины одного порядка и, следовательно, возможна ситуация, когда капля достигнет точки кипения еще в полете. После закипания процесс испарения капли резко ускоряется и практически вся поглощенная каплей энергия излучения уходит на ее испарение. Этому процессу соответствует уравнение энергетического баланса:

$0,934 \cdot \frac{\pi D^{2}}{4} \cdot I_{1} \cdot[1-\eta(D)] \cdot d t=-L \cdot \rho_{w} \cdot \pi D^{2} \cdot d D$, $\frac{d D}{d t}=-\frac{0,934}{4} \cdot \frac{1-\eta(D)}{L \cdot \rho_{w}} \cdot I_{1}$.

Интегрируя (11) от начального диаметра $D$ до конечного $D_{f}$, получим время испарения капли:

$\tau_{e v}=\frac{4,28 \cdot \rho_{w} \cdot L}{I_{1}} \cdot \int_{D_{f}}^{D} \frac{d D}{1-\eta(D)}$.

На рис. 4 представлен расчет зависимости $\tau_{e v 0,9}(D)$ для $D_{f}=0,9 \cdot D$ (частичное испарение капли, рис. $4, a)$ и $\tau_{e v 0}(D)$ для $D_{f}=0$ (полное испарение капли, рис. 4, б).

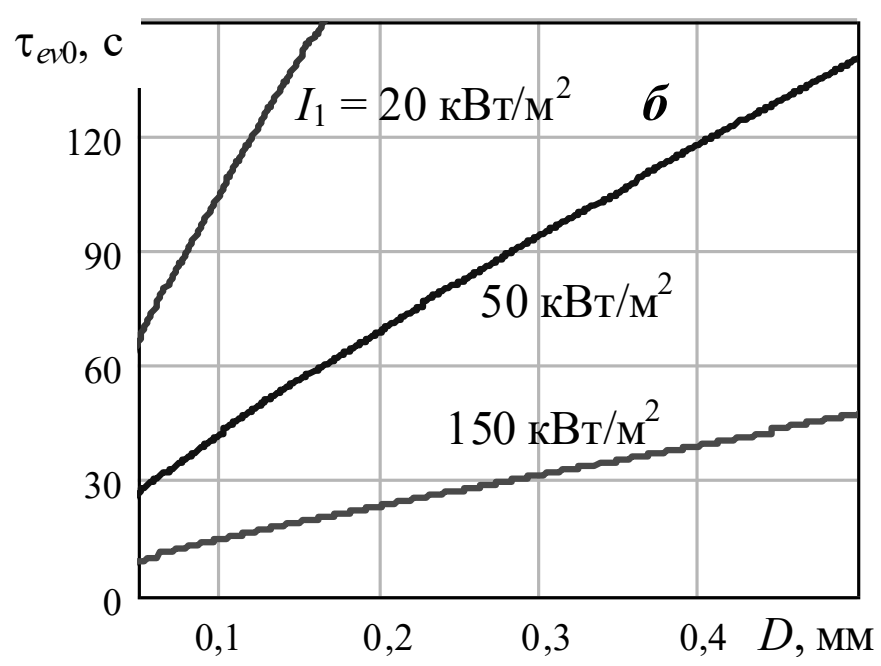

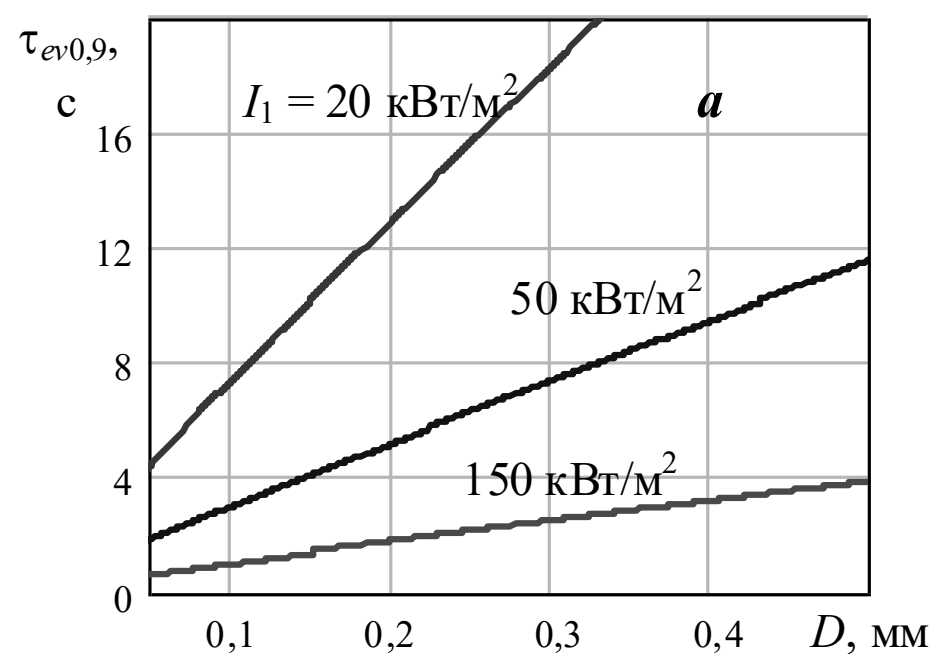

Рис. 4. Время испарения капли, нагретой до точки кипения:

а) частичное испарение (до 0,9.D); б) полное испарение. 
В случае $D_{f}=0,9 \cdot \mathrm{D}$ (рис. $4, a$ ) геометрическая площадь сечения капли уменьшается на $\sim 20 \%$. Такое уменьшение существенно влияет на коэффициент экранирования водяной завесы и должно быть учтено при расчетах, если оно происходит не в самом конце траектории капли, а значительно раньше. Таким образом, условие необходимости учета испарения капель имеет следующий вид:

$\tau_{b}+\tau_{e v 0,9}<<t_{f l}$

Для определенности примем:

$\tau_{b}+\tau_{e v 0,9}<0,5 \cdot t_{f l}$.

С учетом соотношений (9), (10) и (13) получим неравенство:

$$
\begin{aligned}
& \frac{c_{w} \cdot \rho_{w} \cdot D \cdot \Delta T_{b}}{1,4 \cdot(1-\eta) \cdot I_{1}}+\frac{4,28 \cdot \rho_{w} \cdot L}{I_{1}} \cdot \int_{0,9 \cdot D}^{D} \frac{d D}{1-\eta(D)}< \\
& <0,5 \cdot \int_{0}^{h} \frac{\rho_{a} \cdot \Delta z \cdot x \cdot d x}{12,5 \cdot \rho_{w} \cdot b_{0}^{2} \cdot u_{0} \cdot\left(\sqrt{1+\frac{0,42 \cdot \rho_{a} \cdot \Delta z \cdot x \cdot \sin \frac{\varphi_{0}}{2}}{\rho_{w} \cdot \varphi_{0} \cdot b_{0}^{2}}}-1\right)} .
\end{aligned}
$$

Отсюда условие для минимальной интенсивности излучения, выше которой испарение капель необходимо учитывать:

$$
I_{1 \min }=\frac{107 \cdot \rho_{w}^{2} \cdot b_{0}^{2} \cdot u_{0}}{\rho_{a} \cdot \Delta z} \cdot \frac{\frac{c_{w} \cdot D \cdot \Delta T_{b}}{6 \cdot[1-\eta(D)]}+L \cdot \int_{0,9 \cdot D}^{D} \frac{d D}{1-\eta(D)}}{\int_{0}^{h} \frac{x \cdot d x}{\sqrt{1+\frac{0,42 \cdot \rho_{a} \cdot \Delta z \cdot x \cdot \sin \frac{\varphi_{0}}{2}}{\rho_{w} \cdot \varphi_{0} \cdot b_{0}^{2}}}-1}} .
$$

На рис. 5 представлен результат расчета зависимости $I_{1 \min }(D)$ с помощью данной формулы для типичных параметров: $b_{0}=3$ мм, $\varphi_{0}=2,5$ рад, $\Delta z=$ $0,5 \mathrm{~m}, T_{f}=1200 \mathrm{~K}, \Delta T_{b}=80^{\circ} \mathrm{C}, h=10$ м. Варианты задания величин $u_{0}$ указаны на рисунке.

Поскольку в реальных дренчерных оросителях начальная скорость капель, как правило, превышает 20 м/с, то на основе представленных на рис. 5 результатов расчета можно сделать вывод о том, что испарение капель практически не влияет на экранирующие свойства водяных завес даже при максимально возможных интенсивностях излучения пожаров $\sim 100 \ldots 150$ кВт/м².

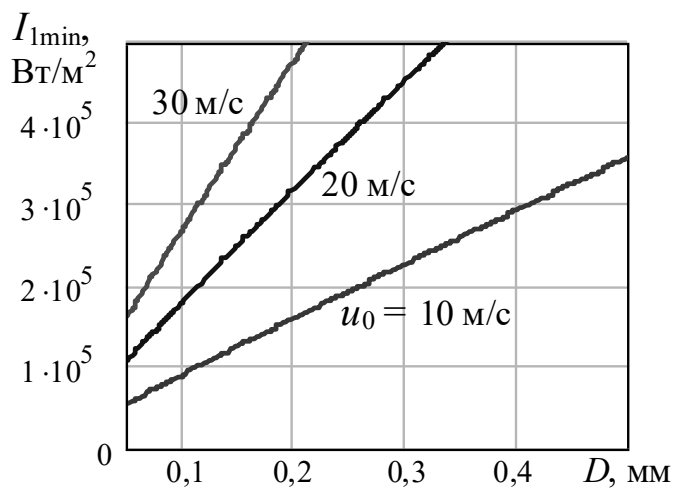

Рис. 5. Минимальная интенсивность излучения, при которой необходим учет испарения капель.

Для верификации полученных результатов используем данные, представленные в работе [9]. В ней выполнено экспериментальное исследование воздействия лазерного излучения с дли-ной волны 10,6 мкм на испарение капель воды радиусом $\sim 1$ мм. Диаметр пучка составлял 3,7 мм, излучение мощностью 3 Вт фокусировалось с помощью линзы на каплю, подвешенную на тонкой нити из стекловолокна диаметром 60 мкм.

Результаты экспериментов указывают на то, что капля начинает испаряться через $\sim 0,5$ с после начала воздействия, и далее радиус капли $R$ изменяется со временем по закону, близкому к линейному. В пределах ошибок измерений скорость испарения капель для интенсивности излучения $40 \div 120 \mathrm{BT} / \mathrm{cm}^{2}$ можно аппроксимировать линейной зависимостью (в единицах СИ) [9]:

$$
\left|\frac{d R}{d t}\right|=2 \cdot 10^{-9}+8,7 \cdot 10^{-11} \cdot I_{1} \text {. }
$$

На основе соотношения (12), подставляя константы, учитывая, что $\eta \rightarrow 0$ при $R \sim 1$ мм и $\lambda$ $=10,6$ мкм, и переходя от диаметра к радиусу капли, получим для скорости испарения:

$\left|\frac{d R}{d t}\right|=5,12 \cdot 10^{-11} \cdot I_{1}$.

При сравнении соотношений (15) и (16) в диапазоне интенсивностей $(4 \div 12) \cdot 10^{5} \mathrm{BT} / \mathrm{M}^{2}$ константой $2 \div 10^{-9}$ в (15) можно пренебречь. Разницу между коэффициентами при I1 в (15) и (16) можно объяснить тем, что, согласно данным 
работы [9], при воздействии мощного лазерного излучения происходит не только испарение капли, но и выброс из нее большого количества (от нескольких сотен до 3 тысяч) мелких частиц (капель) диаметром от 10 до 100 мкм. Очевидно, этот процесс приводит к возрастанию величины $|d R / d t|$.

В целом, согласие экспериментального (15) и теоретического (16) соотношений, с учетом вышеизложенного, можно считать удовлетворительным. Кроме того, простые оценки свидетельствуют о том, что количественное отличие между этими соотношениями не является принципиальным, и сделанный ранее вывод остается в силе и в том случае, если скорректировать (16) с учетом (15).

\section{Вывод}

Для типичных режимов работы противопожарных водяных завес испарение капель вследствие их нагрева тепловым излучением пожара не оказывает существенного влияния на экранирующие свойства водяных завес; при выполнении технических расчетов этот процесс можно не учитывать.

\section{ЛИТЕРАТУРА}

1. Жаров А. Дренчерные завесы: теория и практика / А. Жаров, А. Зархин, М. Митрофанова // БДИ. - 2006 . - № 5 (68). - С. 24-28.

2. Собещзанський Д.І. Водяні завіси в системах забезпечення протипожежного захисту об'єктів різного призначення / Д.І. Собещанський, Г.О. Анохін, Л.А. Склизкова // Науковий вісник
УкрНДІПБ. - 2010 . - № 2 (22). - С. 148-153.

3. Coppalle $A$. Fire protection: water curtains / A. Coppalle, D. Nedelka, B. Bauer // Fire Safety Journal. - 1993. - V. 20. - P. 241-255.

4. Buchlin J.-M. Thermal shielding by water spray curtain / J.-M. Buchlin // Journal of Loss Prevention in the Process Industries. - 2005. - V. 18, No. 4-6. - P. 423-432.

5. Виноградов А.Г. Поглощение лучистого теплового потока в распыленной водяной струе / А.Г. Виноградов // Вісник Національного технічного університету України «Київський політехнічний інститут», сер. Машинобудування. - 2012. - № 65. - С. 145-152.

6. Виноградов А.Г. Методика розрахунків параметрів водяних завіс на основі теорії затоплених струменів / А.Г. Виноградов // Науковий вісник УкрНДІПБ. - 2013. - № 2 (28). - С. 127139.

7. Виноградов А.Г. Методика расчета экранирующих свойств водяных завес / А.Г. Виноградов // Пожаровзрывобезопасность. - 2014. - Т. 23, № 1. - C. 45-56.

8. Виноградов А.Г. Взаимосвязь параметров противопожарных водяных завес с эффективностью экранирования теплового излучения / А.Г. Виноградов, О.М. Яхно, В.А. Дунюшкин // Науковий вісник УкрНДІПБ. - 2015. - № 1 (31). - С. 88-96.

9. Рудаш B.К. Испарение больших капель воды под воздействием инфракрасного излучения / В.К. Рудаш, В.П. Бисярин, Н.М. Ильин и др. // Квантовая электроника. - 1973. - № 5. - С. 21-26. 


\section{INFLUENCE OF PROCESSES OF RADIATION HEAT AND EVAPORATION OF DROPLETS ON THE SHIELDING PROPERTIES OF FIRE WATER CURTAINS}

\section{Vinogradov A.G. ${ }^{1}$, Yakhno O.M. ${ }^{2}$}

${ }^{1}$ Cherkasy Fire Safety Institute named after Chornobyl Heroes, vul. Onoprienko, 8, Cherkasy, 18034, Ukraine

${ }^{2}$ National Technical University of Ukraine "Kyiv Polytechnic Institute", prospect Peremohy, 37, Kyiv, 03056, Ukraine

Water curtains are one of effective means of protection against a fire thermal radiation. The analysis of the water curtain shielding properties is carried out by means of mathematical model operation. A central objective of the study is the analysis of processes of droplets radiant heating and evaporation, and also their influence on the water curtain shielding properties. Main results of the study are the numerical calculations and the graphic dependences of the parameters characterizing droplets evaporation for the typical regimes of thermal shielding. The conclusion follows from the received results that evaporation of droplets owing to their heating by a fire thermal radiation has no essential impact on the shielding properties of water curtains. This process can be not considered when performing technical calculations.

References 9, figures 5.

Key words: fire water curtain; thermal radiation shielding; evaporation of droplets.

1. Zharov A., Zarhin A., Mitrofanova M. Drencher curtains: theory and practice // BDI. -2006 . - № 5 (68) . - P. 24-28. (Rus.)

2. Sobeshhans'kyj D.I., Anohin G.O., Sklyzkova L.A. Water curtains in the systems of ensuring fire protection of various designation objects // Naukovyj visnyk UkrNDIPB. - 2010. - № 2 (22) . - P. 148153. (Ukr.)

3. Coppalle A., Nedelka D., Bauer B. Fire protection: water curtains // Fire Safety Journal. 1993. - V. 20. - P. 241-255.

4. Buchlin J.-M. Thermal shielding by water spray curtain // Journal of Loss Prevention in the Process Industries. - 2005. - V. 18, No. 4-6. - P. 423-432.

5. Vinogradov A.G. Absorption of the radiant heat flux in the sprayed water jet // Vestnik Nacional'nogo tehnicheskogo universiteta Ukrainy «Kievskij politehnicheskij institut», ser. Mashinostroenie. - 2012. - № 65. - P. 145-152. (Rus.)

6. Vinogradov A.G. Calculation method of water curtain parameters on basis of the submerged jet theory // Naukovyj visnyk UkrNDIPB. - 2013. - № 2 (28). - P. 127-139. (Ukr.)

7. Vinogradov A.G. Calculation method of water curtain shielding properties // Pozharovzryvobezopasnost'. - 2014. - T. 23, № 1. - P. 45-56. (Rus.)

8. Vinogradov A.G., Yakhno O.M., Dunjushkin $V$.A. Interrelation of fire water curtains parameters with their heat radiation shielding effectiveness // Naukovyj visnyk UkrNDIPB. - 2015. - № 1 (31). P. 88-96. (Rus.)

9. Rudash V.K., Bisjarin V.P., Il'in N.M. et al. Evaporation of larger water droplets under the influence of an infrared radiation // Kvantovaja jelektronika. - 1973. - № 5. - P. 21-26. (Rus.)

Получено 29.05.2016

Received 29.05.2016 